\title{
Lung adenocarcinoma with intraoperatively diagnosed pleural seeding: Is main tumor resection beneficial for prognosis?
}

\author{
Chi Li, MD, Shuenn-Wen Kuo, MD, Hsao-Hsun Hsu, MD, PhD, Mong-Wei Lin, MD, PhD, and \\ Jin-Shing Chen, MD, PhD
}

\begin{abstract}
Objective: To evaluate whether main tumor resection improves survival compared with pleural biopsy alone in patients with lung adenocarcinoma with intraoperatively diagnosed pleural seeding.

Methods: Forty-three patients with lung adenocarcinoma with pleural seeding diagnosed unexpectedly during surgery performed between January 2006 and December 2014 were included in this retrospective study using a prospectively collected lung cancer database. Each surgeon decided whether to perform main tumor resection or pleural biopsy alone.
\end{abstract}

Results: Main tumor and visible pleural nodule resection was performed in 30 patients (tumor resection group). The remaining 13 patients underwent pleural nodule biopsy alone (open-close group). The clinical $\mathrm{T}$ stage was higher in the open-close group than in the tumor resection group $(P=.02)$. The tumor resection group had longer operative times compared with the open-close group (mean, 141.8 vs 80.3 minutes). There were no other statistically significant differences in perioperative parameters. The surgical method was the sole statistically significant prognostic factor. Patients in the tumor resection group had better progression-free survival (3-year survival: $44.5 \%$ vs $0 \% ; P=.009$ ) and overall survival (3-year survival: $82.9 \%$ vs $38.5 \% ; P=.013$ ) than did the open-close group. There was no significant survival difference between sublobar resection and lobectomy for the main tumor resection.

Conclusions: Our study demonstrated improved progression-free and overall survival after main tumor and visible pleural nodule resection in patients with lung adenocarcinoma with intraoperatively diagnosed pleural seeding. Further randomized trials are needed to define the role of main tumor resection in these patients. (J Thorac Cardiovasc Surg 2018;155:1238-49)

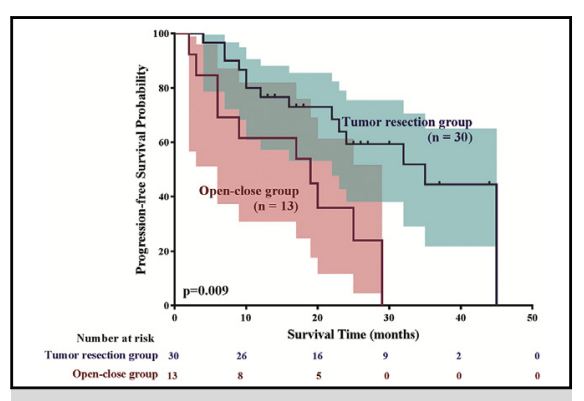

Survival was superior in the tumor resection group compared with the open-close group.

\section{Central Message}

Main tumor and visible pleural nodule resection may improve progression-free and overall survival in patients with lung adenocarcinoma with intraoperatively diagnosed pleural seeding.

\section{Perspective}

Main tumor and visible pleural nodule resection followed by multimodality adjuvant therapy achieved better survival than pleural biopsy alone in patients with lung adenocarcinoma intraoperatively diagnosed pleural seeding. There was no significant survival difference between sublobar resection and lobectomy as the main tumor resection. Randomized trials are needed to confirm these results.

See Editorial Commentaries pages 1250 and 1252 .

See Editorial page 1207.
Lung cancer is the leading cause of cancer deaths worldwide. ${ }^{1}$ Surgical resection is the treatment of choice for early-stage non-small cell lung cancer (NSCLC), whereas systemic

From the Department of Surgery, National Taiwan University Hospital and National Taiwan University College of Medicine, Taipei, Taiwan.

C. L. and S.-W.K. contributed equally as first authors to this work.

This study was supported by research grants from the Ministry of Science and Technology, Taiwan (NSC105-2628-B-002-011-MY2) and National Taiwan University Hospital, Taipei, Taiwan (NTUH106-N003667, MS419).

Read at the 97th Annual Meeting of The American Association for Thoracic Surgery, Boston, Massachusetts, April 29-May 3, 2017.

Received for publication March 22, 2017; revisions received Sept 18, 2017; accepted for publication Sept 30, 2017; available ahead of print Dec 16, 2017. chemotherapy is the standard of care for patients with stage IV disease. ${ }^{2}$ In the 7 th edition of the American Joint Committee on Cancer's TNM staging system for lung cancer, pleural

\footnotetext{
Address for reprints: Mong-Wei Lin, MD, PhD, Department of Surgery, National Taiwan University Hospital and Taiwan University College of Medicine, No. 7, Chung-Shan South Rd, Taipei 10002, Taiwan (E-mail: mwlin@ntu.edu.tw) 0022-5223

Copyright (C) 2017 by The American Association for Thoracic Surgery. This is an open access article under the CC BY-NC-ND license (http://creativecommons.org/ licenses/by-nc-nd/4.0/).

https://doi.org/10.1016/j.jtcvs.2017.09.162
} 


\section{Abbreviations and Acronyms}
ALK = anaplastic lymphoma kinase
$\mathrm{CI}=$ confidence interval
CT = computed tomography
EGFR = epidermal growth factor receptor
MRI = magnetic resonance imaging
MST = median survival time
NSCLC $=$ non-small cell lung cancer
OS $=$ overall survival
PET = positron emission tomography
PFS = progression-free survival
TKI $=$ tyrosine kinase inhibitor
VATS $=$ video-assisted thoracoscopic surgery

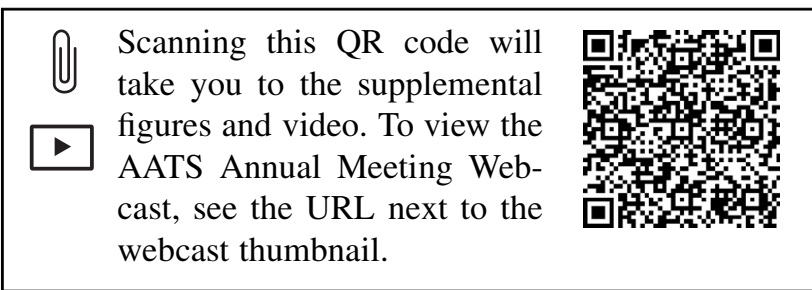

seeding and malignant pleural effusion were reclassified from T4 to M1a. ${ }^{3}$ The 2017 th edition of this staging system maintained the classification. ${ }^{4}$ Patients with NSCLC with M1a metastases have poor outcomes, with a median survival time (MST) of 11.5 months, and M1a metastasis is generally considered a contraindication for curative main tumor resection. ${ }^{5}$

Patients with M1a metastases present with a range of disease severity, from minimal disease with only a single small pleural seeding and no malignant pleural effusion to advanced disease with multiple large pleural nodules and massive malignant pleural effusion. ${ }^{6}$ Occasionally, thoracic surgeons detect unexpected pleural nodules intraoperatively in patients in clinical stage $\mathrm{M} 0$ with what was presumed to be operable disease. Intraoperatively diagnosed pleural seeding is usually localized and small, evading detection on preoperative imaging. If pleural seeding is detected unexpectedly during surgery and confirmed by frozen section, the current consensus favors open-close surgery followed by chemotherapy or targeted therapy for stage IV disease. ${ }^{7}$

Recently, improved multimodality treatment options have become available for stage IV NSCLC, including new chemotherapy regimens, epidermal growth factor receptor (EGFR) tyrosine kinase inhibitors (TKIs), anaplastic lymphoma kinase (ALK) TKIs, and immunotherapy. Photodynamic therapy and hyperthermic intrapleural chemotherapy may represent beneficial alternatives for patients with malignant pleural disease. ${ }^{10}$ In addition, developments in minimally invasive surgery and postoperative care have improved surgical outcomes and decreased surgery-related morbidity. ${ }^{11,12}$ Several recent studies have reported the use of curative surgery in NSCLC with intraoperatively diagnosed pleural seeding, showing a survival benefit of main tumor resection. ${ }^{13-18}$ However, the long-term outcomes of these patients are not known, and there is no consensus regarding the appropriate surgical approach. We thus evaluated whether resection of the main tumor improved survival compared with pleural biopsy alone in patients with intraoperatively diagnosed pleural seeding. Given that adenocarcinoma is the most common histology in patients with NSCLC with pleural carcinomatosis, with a reported prevalence of $64 \%$ to $87.2 \%,{ }^{13-19}$ we evaluated only patients with histologically proven adenocarcinoma.

\section{METHODS \\ Patients}

We retrospectively reviewed charts from 4591 consecutive patients with lung cancer undergoing surgical resection between January 2006 and December 2014. Data were obtained from a prospectively collected database at the National Taiwan University Hospital. The 4591 patients included $55(1.2 \%)$ with NSCLC with pleural seeding diagnosed unexpectedly during surgery. We excluded 12 patients, including 7 with multiple lung tumors, 2 with a histological type other than adenocarcinoma (lymphoepithelioma-like carcinoma), 1 with clinical N3 staging before surgery, and 2 lost to postoperative follow-up. Finally, 43 patients with a single lung adenocarcinoma and pleural seeding diagnosed unexpectedly during surgery were included. Main tumor and visible pleural nodule resection was performed in 30 patients (tumor resection group). The remaining 13 patients underwent pleural nodule biopsy alone (open-close group). Clinicopathological parameters were collected from the lung cancer database. Clinical T and N stages were classified according to the American Joint Committee on Cancer's 8th TNM Classification for Lung and Pleural Tumors. ${ }^{4}$ The National Taiwan University Hospital Research Ethics Committee approved the study (project approval no. 201601006RINC; approval date, February 16, 2016) and waived informed consent for this retrospective study.

Preoperative staging procedures included chest radiography, blood chemistry analysis and serum carcinoembryonic antigen measurement, brain computed tomography (CT) or magnetic resonance imaging (MRI), chest and abdominal CT, positron emission tomography (PET) scanning or bone scanning, and pulmonary function tests. All imaging studies were performed within 2 months preoperatively. Chest ultrasonography for thoracentesis was performed routinely in patients with preoperatively noted pleural effusion, and patients with preoperatively confirmed malignant pleural effusion (M1a) were excluded. Neither image-detected pleural seeding nor distant metastases were noted preoperatively in the final study population. All tumors were preoperatively staged as resectable in the 43 study patients.

\section{Patient Follow-up}

Patients were regularly monitored in the outpatient clinic with physical examination, serum carcinoembryonic antigen measurement, brain CT, and chest CT every 3 months for the first 2 years. Thereafter, patients were regularly monitored with similar examinations every 3 to 6 months according to the attending physician's instructions.

Bronchoscopy, brain CT, brain MRI, PET, lymph node biopsy, chest ultrasound, and other tests were performed whenever any symptoms or signs of tumor recurrence were noted. Local progression was defined as main tumor enlargement in the open-close group and as lesion recurrence at the resection margin in the tumor resection group. Regional progression was defined as malignant pleural effusion or pleural nodules, new lung lesions, or ipsilateral lymph node recurrence. Lymph node recurrence was defined 
as a hypermetabolic node diagnosed via PET or a lymph node $\geq 1 \mathrm{~cm}$ in the short axis on chest CT. Distant metastasis was defined as a metastatic lesion in the contralateral lung or any other organ. A diagnosis of recurrence was further confirmed cytologically or histologically by thoracentesis of a malignant pleural effusion, needle biopsy, or surgical biopsy when clinically necessary and feasible.

\section{Statistical Analysis}

Patient clinicopathological characteristics, surgical procedures, surgical approaches, and patient outcomes were compared between groups using Fisher's exact test for categorical variables (frequency and percentage) and the Wilcoxon rank-sum test for continuous variables (mean, standard deviation, and range). Progression-free survival (PFS) was defined as the time from surgery to any disease progression. Overall survival (OS) was defined as the time from surgery to death or the last follow-up. PFS and OS were tested using Kaplan-Meier survival plots and analyzed with log-rank tests. Prognostic factors for PFS and OS were analyzed by univariate analysis, and comparisons were made using log-rank tests. Subsequently, a multivariable Cox proportional hazards model was fitted and adjusted for several parameters, including tumor size, clinical N stage, malignant pleural effusion, degree of pleural nodule dissemination, preoperative PET, and EGFR mutation status. Results are presented as hazard ratio and $95 \%$ confidence intervals (CIs). All tests were 2-sided, and a $P$ value $<.05$ was considered to indicate statistical significance. Data were analyzed using SPSS version 23 (IBM, Armonk, NY) and Stata 13 (StataCorp, College Station, Tex).

\section{RESULTS \\ Patient Demographics and Clinicopathological Characteristics}

We evaluated 43 patients with single lung adenocarcinoma and pleural seeding diagnosed unexpectedly intraoperatively. The mean duration of follow-up was 28.0 months (range, 4118 months). The mean age was 58 years (range, 2980 years), and $74.4 \%$ of patients were nonsmokers ( 32 of 43). Females accounted for $62.8 \%$ of the study patients ( 27 of 43). Twenty-three patients $(53.5 \% ; 23$ of 43$)$ were in clinical stage $\mathrm{T} 1$, and 30 patients $(69.8 \% ; 30$ of 43$)$ were in clinical stage N0. An EGFR mutation was noted in $58.1 \%$ of patients. The clinical $\mathrm{T}$ stage was higher in the open-close group than in the tumor resection group $(P=.02)$. There were no other significant differences between the 2 groups. Other demographic data, clinicopathological characteristics, preoperative staging workup, and neoadjuvant and adjuvant treatments of the entire study group are presented in Table 1.

\section{Operative and Perioperative Results}

All patients initially underwent video-assisted thoracoscopic surgery (VATS). Pleural nodules were found unexpectedly (Figure 1) and were pathologically confirmed by intraoperative frozen sections to be pleural seeding. The degree of pleural metastasis was defined as localized if 3 or fewer pleural nodules were found. Otherwise, the degree of pleural metastasis was defined as diffused. ${ }^{13}$ Pleural metastasis was localized and diffused in 4 and 39 patients, respectively. Malignant pleural effusion was present in 8 patients $(18.6 \%)$ (Table 2$)$.
Following the confirmation of pleural seeding, surgery was either terminated (open-close group; $n=13$ ) or preceded to main tumor and visible pleural nodule resection (tumor resection group; $\mathrm{n}=30$ ). The choice of main tumor resection or pleural biopsy alone was at the surgeon's discretion. In the tumor resection group, patients had a significantly lower clinical T stage $(P=.02)$ and tended to have localized pleural metastasis $(P=.30 ; 13.3 \%$ vs $0 \%)$. To completely remove grossly visible pleural metastases located in the same area with adequate resection margin, pleurectomy was performed in 14 of the 30 patients $(46.7 \%)$ in the tumor resection group (Figure E1). The other 16 patients underwent removal or ablation of visible pleural nodules without pleurectomy. All patients underwent pleural biopsy alone for diagnostic purposes in the pleural biopsy group.

Seventeen of the 30 patients in the tumor resection group underwent segmentectomy $(\mathrm{n}=1)$ or wedge resection $(\mathrm{n}=16)$. The remaining 13 underwent lobectomy for main tumor removal. Systematic lymph node dissection was performed in all patients who underwent anatomic resection, including lobectomy $(\mathrm{n}=13)$ and segmentectomy $(\mathrm{n}=1)$. Mediastinal lymph node dissection was performed in 9 of the 16 patients who underwent wedge resection $(56.3 \%)$. The remaining patients underwent resection of the main tumor and visible pleural nodules only. Operative times were longer in the tumor resection group compared with the open-close group (mean, 141.8 vs 80.3 minutes; $P<.001$ ). There were no other statistically significant between-group differences in perioperative outcomes, including operative bleeding, postoperative hospital stay, morbidity, and mortality (Table 2). In the open-close group, 5 of 13 patients (38.5\%) received a first course of adjuvant chemotherapy while hospitalized. In contrast, all patients in the tumor resection group received adjuvant treatment after discharge. Therefore, the mean hospital stay was longer in the open-close group than in the tumor resection group (8.2 vs 6.9 days). Three complications occurred overall. One patient from the open-close group experienced postoperative bleeding. Two patients from the tumor resection group had vocal cord palsy, with prolonged ventilator support and intraoperative bleeding, respectively. Only the patient who underwent lobectomy and experienced massive intraoperative bleeding underwent conversion from VATS to traditional thoracotomy for hemostasis. The remaining surgeries were performed with VATS.

\section{Neoadjuvant and Adjuvant Treatment}

Among the 43 patients, $9(20.9 \%)$ underwent neoadjuvant treatment, including 8 who received chemotherapy and 1 who received EGFR TKI therapy. One patient in the open-close group and 7 patients in the tumor resection group received platinum-based neoadjuvant chemotherapy. The remaining patient in the tumor resection group received neoadjuvant EGFR TKI therapy (Table 1). Two patients underwent surgery before January 2008, and both received 
TABLE 1. Clinicopathological characteristics of the 43 patients with lung adenocarcinoma with intraoperatively diagnosed pleural seeding

\begin{tabular}{|c|c|c|c|c|}
\hline \multirow[b]{2}{*}{ Variables } & \multirow[b]{2}{*}{ Total, $\mathbf{n}(\%)$ or mean } & \multicolumn{2}{|c|}{ Surgical methods, $n(\%)$ or mean \pm SD $($ range $)$} & \multirow[b]{2}{*}{$P$ value } \\
\hline & & Open-close group & Tumor resection group & \\
\hline Number of patients & 43 & 13 & 30 & \\
\hline $\begin{array}{l}\text { Sex } \\
\quad \text { Female } \\
\text { Male }\end{array}$ & $\begin{array}{l}27(62.8) \\
16(37.2)\end{array}$ & $\begin{array}{l}8(61.5) \\
5(38.5)\end{array}$ & $\begin{array}{l}19(63.3) \\
11(36.7)\end{array}$ & .91 \\
\hline Age, y & 57.7 & $56.9 \pm 18.1(29-79)$ & $58.0 \pm 11.1(33-80)$ & .85 \\
\hline $\begin{array}{l}\text { Smoking status } \\
\text { Nonsmoker } \\
\text { Smoker }\end{array}$ & $\begin{array}{l}32(74.4) \\
11(25.6)\end{array}$ & $\begin{array}{r}11(84.6) \\
2(15.4)\end{array}$ & $\begin{array}{r}21(70.0) \\
9(30.0)\end{array}$ & .31 \\
\hline $\begin{array}{l}\text { Comorbidities } \\
\text { DM } \\
\text { Hypertension } \\
\text { ESRD } \\
\text { Other malignancies }\end{array}$ & $\begin{array}{l}7(16.3) \\
8(18.6) \\
1(2.3) \\
5(11.6)\end{array}$ & $\begin{array}{l}3(23.1) \\
3(23.1) \\
0(0) \\
3(23.1)\end{array}$ & $\begin{array}{l}4(13.3) \\
5(16.7) \\
1(3.3) \\
2(6.7)\end{array}$ & $\begin{array}{l}.42 \\
.62 \\
.50 \\
.12\end{array}$ \\
\hline $\begin{array}{l}\text { Preoperative lung function* } \\
\mathrm{FEV}_{1}, \% \\
\mathrm{FVC}, \%\end{array}$ & $\begin{array}{l}98.6 \\
98.7\end{array}$ & $\begin{array}{l}95.1 \pm 30.6(46.3-146.6) \\
95.3 \pm 18.2(67.7-126.8)\end{array}$ & $\begin{array}{l}100 \pm 16.4(58.2-127.5) \\
100 \pm 17.3(56.9-126.0)\end{array}$ & $\begin{array}{l}.56 \\
.38\end{array}$ \\
\hline $\begin{array}{l}\text { Staging workup } \\
\text { Bone scan } \\
\text { PET scan }\end{array}$ & $\begin{array}{l}22(51.2) \\
21(48.8)\end{array}$ & $\begin{array}{l}7(53.8) \\
6(46.2)\end{array}$ & $\begin{array}{l}15(50.0) \\
15(50.0)\end{array}$ & 1.00 \\
\hline $\begin{array}{l}\text { Staging workup for brain metastasis } \\
\text { CT } \\
\text { MRI }\end{array}$ & $\begin{array}{l}31(73.8) \\
11(26.2)\end{array}$ & $\begin{array}{r}11(84.6) \\
2(15.4)\end{array}$ & $\begin{array}{r}20(69.0) \\
9(31.0)\end{array}$ & .45 \\
\hline $\begin{array}{c}\text { ECOG } \\
0 \\
1\end{array}$ & $\begin{array}{l}21(48.8) \\
22(51.2)\end{array}$ & $\begin{array}{l}6(46.2) \\
7(53.8)\end{array}$ & $\begin{array}{l}15(50.0) \\
15(50.0)\end{array}$ & .82 \\
\hline Tumor size, $\mathrm{cm}$ & 2.9 & $3.3 \pm 1.3(1.8-5.8)$ & $2.7 \pm 0.9(1.3-4.3)$ & .15 \\
\hline $\begin{array}{l}\text { Clinical T stage } \\
\text { T1 } \\
\mathrm{T} 2 \\
\mathrm{~T} 3 \dagger\end{array}$ & $\begin{array}{c}23(53.5) \\
17(39.5) \\
3(5.7)\end{array}$ & $\begin{array}{l}7(53.8) \\
3(23.1) \\
3(23.1)\end{array}$ & $\begin{array}{c}16(53.3) \\
14(46.7) \\
0(0)\end{array}$ & .02 \\
\hline $\begin{array}{l}\text { Clinical N stage } \\
\text { N0 } \\
\text { N1 } \\
\text { N2 }\end{array}$ & $\begin{aligned} 30 & (69.8) \\
2 & (4.7) \\
11 & (25.6)\end{aligned}$ & $\begin{array}{l}10(76.9) \\
0(0) \\
3(23.1)\end{array}$ & $\begin{array}{l}20(66.7) \\
2(6.7) \\
8(26.7)\end{array}$ & .65 \\
\hline EGFR mutation & $25(58.1)$ & $7(53.8)$ & $18(60.0)$ & .71 \\
\hline $\begin{array}{l}\text { Neoadjuvant treatment } \\
\text { Chemotherapy } \\
\text { EGFR TKI }\end{array}$ & $\begin{array}{l}8(18.6) \\
1(2.3)\end{array}$ & $\begin{array}{l}1(7.7) \\
0(0)\end{array}$ & $\begin{array}{l}7(23.3) \\
1(3.3)\end{array}$ & $\begin{array}{l}.23 \\
.51\end{array}$ \\
\hline $\begin{array}{l}\text { Adjuvant treatment } \\
\text { Chemotherapy } \\
\text { Radiotherapy } \\
\text { EGFR TKI }\end{array}$ & $\begin{array}{r}21(48.8) \\
7(16.3) \\
29(67.4)\end{array}$ & $\begin{array}{l}8(61.5) \\
4(30.8) \\
8(61.5)\end{array}$ & $\begin{array}{r}13(43.3) \\
3(10.0) \\
21(70.0)\end{array}$ & $\begin{array}{l}.27 \\
.09 \\
.59\end{array}$ \\
\hline
\end{tabular}

$S D$, Standard deviation; $D M$, diabetes mellitus; $E S R D$, end-stage renal disease; $F E V_{l}$, forced expiratory volume in 1 second; $F V C$, forced vital capacity; $P E T$, positron emission tomography; $C T$, computed tomography; MRI, magnetic resonance imaging; ECOG, Eastern Cooperative Oncology Group; EGFR, epidermal growth factor receptor; TKI, tyrosine kinase inhibitor. *Three patients did not undergo pulmonary function testing before surgery. $\dagger$ According to the American Joint Committee on Cancer's 8th Edition of the TNM classification, 3 patients with tumor size 5 to $6 \mathrm{~cm}$ were classified as T3.

platinum-based chemotherapy as first-line adjuvant treatment. Tumor specimens $(\mathrm{n}=41)$ obtained after January 2008 were sent for EGFR mutation analysis postoperatively. EGFR TKIs, including gefitinib (Iressa) or erlotinib
(Tarceva), were prescribed for all patients with positive $E G F R$ mutations and as an alternative second-line treatment for patients without ERGR mutations. Platinum-based chemotherapy was prescribed within 1 month 

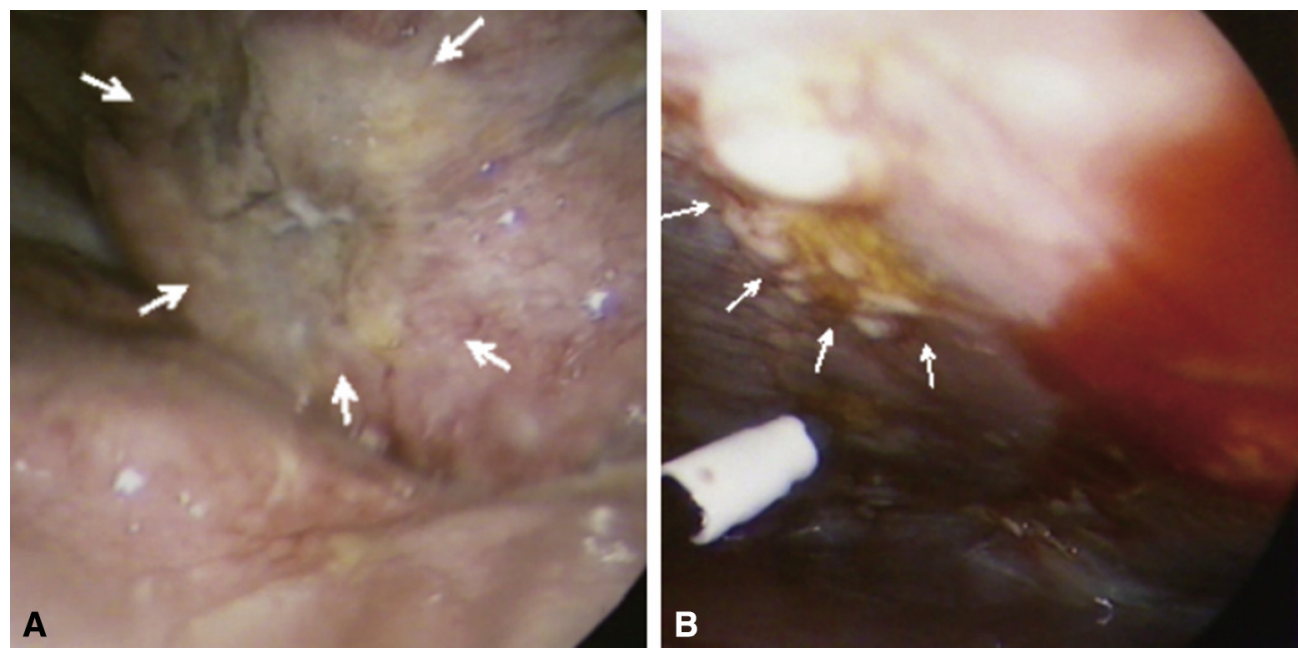

FIGURE 1. A, Thoracoscopic view of the right upper lobe main tumor (arrow). B, Thoracoscopic view of localized pleural seeding (arrow) located on the lower chest wall near the reflection of the diaphragm.

postoperatively for all wild-type EGFR cases or as salvage therapy when targeted therapy failed. Radiotherapy was administered in 7 patients for local tumor progression or distant metastasis control, based on the treatment plan developed by a multidisciplinary lung cancer team. Four patients with positive ALK rearrangement ( 2 in the tumor resection group and 2 in the open-close group) received ALK TKI (crizotinib, Xalkori) treatment after disease progression. One patient in the open-close group underwent a second surgery for radical pleurectomy and photodynamic therapy when malignant pleural effusion and progressive pleural seeding were noted during follow-up.

TABLE 2. Perioperative and postoperative results

\begin{tabular}{|c|c|c|c|}
\hline \multirow[b]{2}{*}{ Variables } & Open-close group & Tumor resection group & \multirow[b]{2}{*}{$P$ value } \\
\hline & \multicolumn{2}{|c|}{$\mathbf{N}(\%)$ or mean \pm SD (range) } & \\
\hline Number of patients & 13 & 30 & \\
\hline $\begin{array}{l}\text { Surgical method for main } \\
\text { tumor }\end{array}$ & & & $<.001$ \\
\hline Pleural biopsy alone & $13(100.0)$ & $0(0)$ & \\
\hline Sublobar resection & $0(0)$ & $17(56.7)$ & \\
\hline Lobectomy & $0(0)$ & $13(43.3)$ & \\
\hline Pleurectomy & & & .003 \\
\hline No & $13(100.0)$ & $16(53.3)$ & \\
\hline Yes & $0(0)$ & $14(46.7)$ & \\
\hline Surgical time (min) & $80.3 \pm 16.5(55-110)$ & $141.8 \pm 34.4(83-205)$ & $<.001$ \\
\hline Operative bleeding $(\mathrm{mL})$ & & & .16 \\
\hline$\leq 50$ & $13(100.0)$ & $24(80.0)$ & \\
\hline$>50$ & $0(0)$ & $6(20.0)$ & \\
\hline Malignant pleural effusion & & & .22 \\
\hline Absent & $9(69.2)$ & $26(86.7)$ & \\
\hline Present & $4(30.8)$ & $4(13.3)$ & \\
\hline Pleural nodule & & & .30 \\
\hline Localized & $0(0)$ & $4(13.3)$ & \\
\hline Diffused & $13(100)$ & $26(86.7)$ & \\
\hline Postoperative hospital stay (d) & $8.2 \pm 5.0(3-18)$ & $6.9 \pm 6.0(2-36)$ & .34 \\
\hline Morbidity & $1(7.7)$ & $2(6.7)$ & 1.00 \\
\hline Mortality & $0(0)$ & $0(0)$ & \\
\hline
\end{tabular}

SD, Standard deviation. 
TABLE 3. Correlations between clinicopathological features, EGFR mutation status, postoperative therapy, and survival: univariate analysis

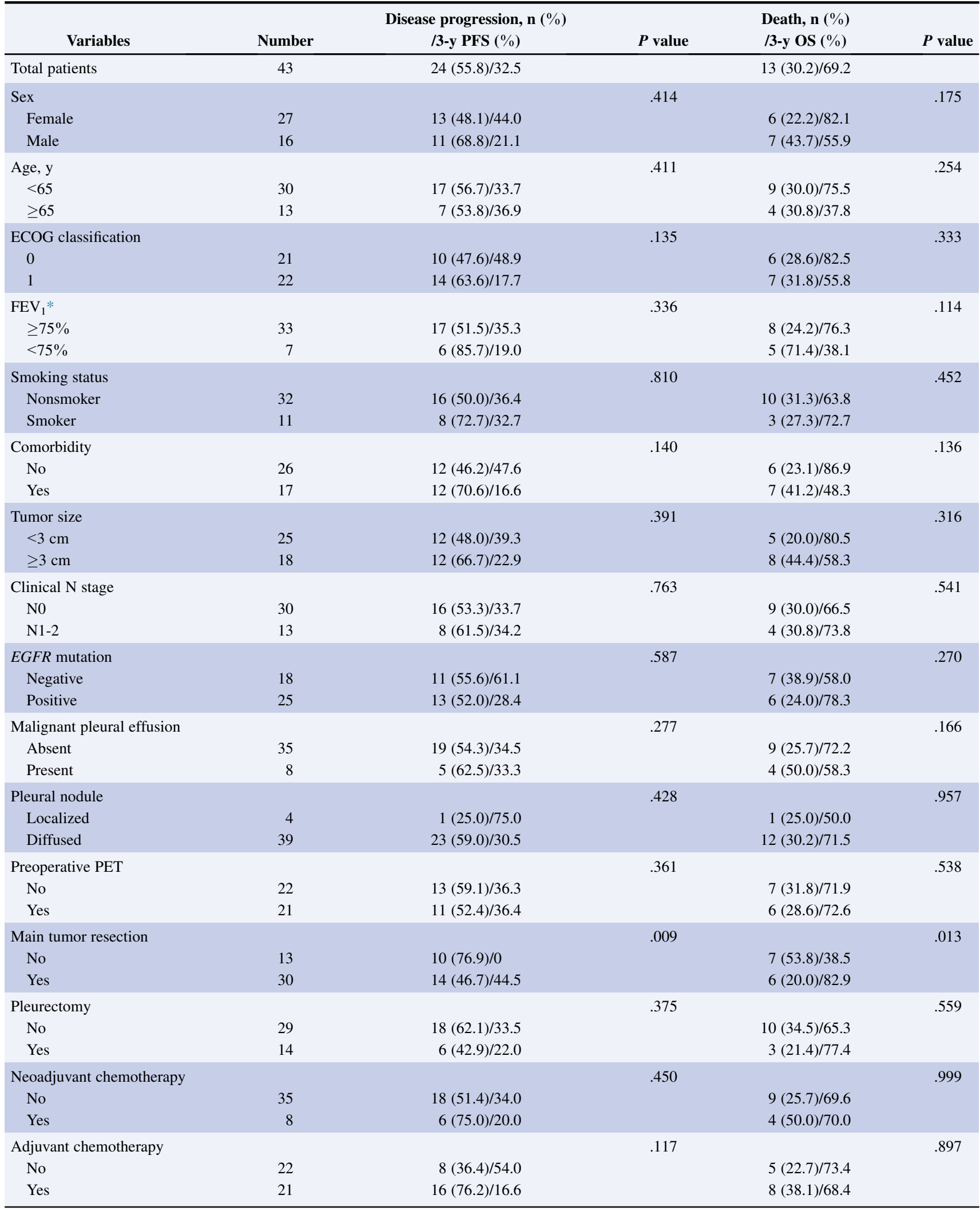


TABLE 3. Continued

\begin{tabular}{|c|c|c|c|c|c|}
\hline & & Disease progression, $n(\%)$ & & Death, n (\%) & \\
\hline Variables & Number & /3-y PFS $(\%)$ & $P$ value & /3-y OS (\%) & $P$ value \\
\hline Adjuvant TKI treatment & & & .495 & & .226 \\
\hline No & 14 & $9(64.3) / 36.7$ & & $6(42.9) / 46.9$ & \\
\hline Yes & 29 & $15(51.7) / 31.6$ & & $7(24.1) / 81.1$ & \\
\hline
\end{tabular}

$P F S$, Progression-free survival; $O S$, overall survival; $E C O G$, Eastern Cooperative Oncology Group; $F E V_{l}$, forced expiratory volume in 1 second; $E G F R$, epidermal growth factor receptor; $P E T$, positron emission tomography; TKI, tyrosine kinase inhibitor. *Three patients did not undergo pulmonary function testing before surgery.

\section{Correlation Among Clinicopathological Features, EGFR Mutation Status, Postoperative Therapies, and Clinical Outcomes}

The 3-year PFS and OS for all patients were 32.5\% and $69.2 \%$, respectively. Kaplan-Meier survival analysis with a log-rank test demonstrated that the surgical method was the sole statistically significant prognostic factor (Tables 3 and 4). Patients in the tumor resection group had better PFS $(P=.009$; MST: 35 months [95\% CI, 18.1-51.9 months] vs 19 months [95\% CI, 2.4-35.6 months]) and OS $(P=.013$; MST: 64 months [95\% CI, 25.8-102.2 months] vs 35 months [ $95 \%$ CI, 14.3-55.7 months]) compared with the open-close group (Figure 2, $A$ and $B$ ). The 6-month, 1year, and 3-year PFS rates were $96.7 \%, 76.7 \%$, and $44.5 \%$, respectively, in the tumor resection group and $69.2 \%$, $61.5 \%$, and $0 \%$, respectively, in the open-close group. The median PFS was 35 months in the tumor resection group and 19 months in the open-close group.

Similar results were found for OS. The 6-month, 1-year, and 3-year OS rates were $96.7 \%, 89.8 \%$, and $82.9 \%$, respectively, in the tumor resection group and $84.6 \%$, $76.9 \%$, and $38.5 \%$, respectively, in the open-close group. The median OS was 64 months in the tumor resection group and 35 months in the open-close group.
In the tumor resection group, 17 patients underwent sublobar resection and 13 underwent lobectomy. KaplanMeier survival analysis with a log-rank test showed that there was no significant between-group (sublobar resection vs lobectomy) difference for PFS $(P=.754$; MST: 32 months [95\% CI, 19.0-45.0 months] vs 35 months [95\% CI, 24.3-45.7 months]) or OS $(P=.429$; MST: 37 months [95\% CI, 2.1-71.9 months] vs 64 months [95\% CI, 15.9-112.1 months]) (Figure E2).

\section{Disease Progression Patterns}

Tumor progression was noted in 24 patients. Seventeen experienced local progression, 19 experienced regional progression, and 16 had distant metastases. Tumor progression was diagnosed by CT in $41.7 \%$ of these patients, by biopsy (thoracentesis of malignant pleural effusion, needle biopsy, or surgical biopsy) in $25 \%$, by brain MRI in $20.8 \%$, and by PET in $12.5 \%$. Distant metastatic sites included the contralateral lung $(\mathrm{n}=7)$, brain $(\mathrm{n}=7)$, bone $(\mathrm{n}=3)$, skin $(\mathrm{n}=2)$, and adrenal gland $(\mathrm{n}=1)$. Three of the 16 patients $(18.8 \%)$ with distant metastases had more than 1 site of recurrence at diagnosis.

We analyzed the disease progression patterns to clarify the differences in survival between the tumor resection

TABLE 4. Correlations among clinicopathological features, EGFR mutation status, postoperative therapy, and survival: multivariate analysis

\begin{tabular}{|c|c|c|c|c|c|c|}
\hline \multirow[b]{2}{*}{ Variables } & \multicolumn{3}{|c|}{ Progression-free survival } & \multicolumn{3}{|c|}{ Overall survival } \\
\hline & HR & $95 \%$ CI & $P$ value & HR & $95 \% \mathrm{CI}$ & $\overline{P \text { value }}$ \\
\hline \multicolumn{7}{|l|}{ Main tumor resection } \\
\hline Yes vs no & 0.340 & $0.134-0.861$ & .023 & 0.239 & $0.066-0.873$ & .030 \\
\hline \multicolumn{7}{|l|}{ Tumor size } \\
\hline$\geq 3 \mathrm{~cm} \mathrm{vs}<3 \mathrm{~cm}$ & 1.566 & $0.658-3.724$ & .311 & 1.692 & $0.511-5.606$ & .390 \\
\hline \multicolumn{7}{|l|}{$\mathrm{N}$ stage } \\
\hline $1-2$ vs 0 & 0.780 & $0.233-2.613$ & .687 & 0.157 & $0.022-1.138$ & .067 \\
\hline \multicolumn{7}{|l|}{ Malignant pleural effusion } \\
\hline Present vs absent & 1.030 & $0.289-3.678$ & .963 & 3.036 & $0.525-17.553$ & .215 \\
\hline \multicolumn{7}{|l|}{ Pleural nodule } \\
\hline Diffused vs localized & 1.336 & $0.164-10.914$ & .787 & 0.269 & $0.024-3.001$ & .286 \\
\hline \multicolumn{7}{|l|}{ Preoperative PET } \\
\hline Yes vs no & 1.980 & $0.739-5.301$ & .174 & 3.324 & $0.666-16.591$ & .143 \\
\hline \multicolumn{7}{|l|}{ EGFR } \\
\hline Positive vs negative & 0.693 & $0.255-1.886$ & .473 & 0.233 & $0.054-1.003$ & .050 \\
\hline
\end{tabular}

$H R$, Hazard ratio; $C I$, confidence interval; PET, positron emission tomography; EGFR, epidermal growth factor receptor. 

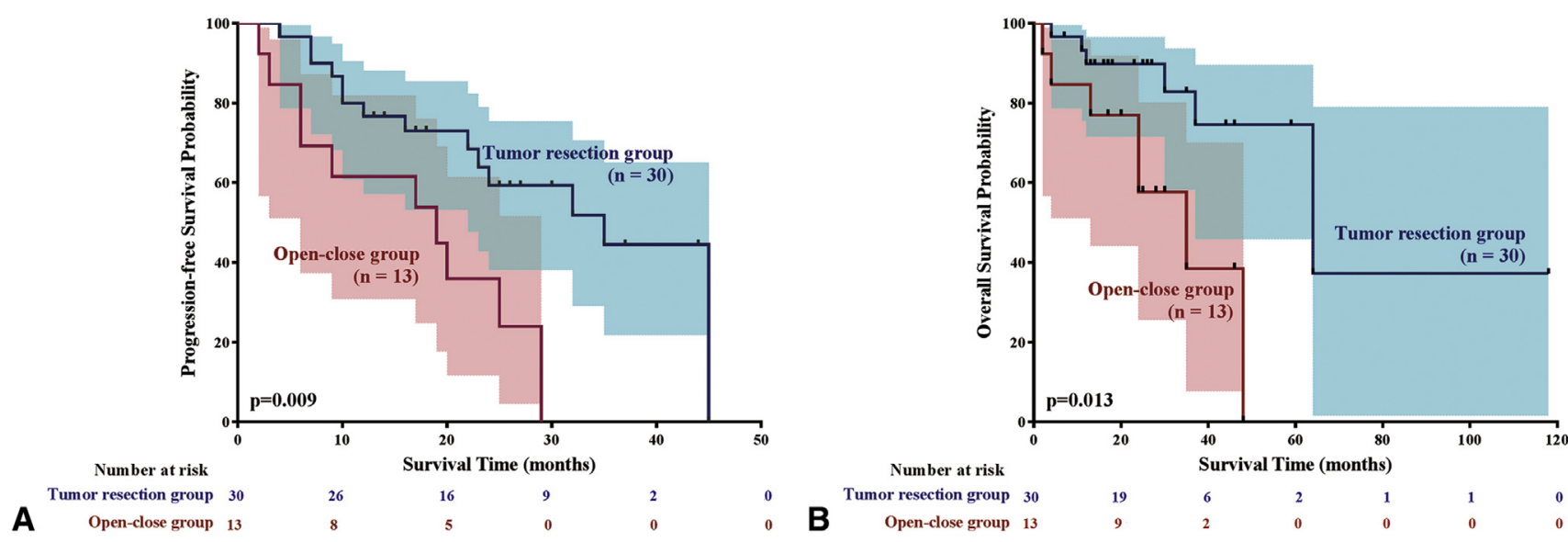

FIGURE 2. Kaplan-Meier survival curves of progression-free survival (A) and overall survival (B) of the study groups.

and the open-close groups. As shown in Figure 3, $A$ and $B$, compared with the open-close group, the tumor resection group had a significantly greater local progression-free duration (3-year probability, $67.8 \%$ vs $35.9 \% ; P=.002$ ) and regional progression-free duration (3-year probability, $61.5 \%$ vs $20.8 \% ; P=.026$ ). There was no significant between-group difference in the time from surgery to the detection of distant metastasis (3-year probability, 75.7\% vs $22.7 \% ; P=.083$ ), but the time to metastasis detection tended to be longer in the tumor resection group (Figure 3,C).

\section{DISCUSSION}

Pleural seeding generally conveys a poor prognosis in patients with NSCLC. ${ }^{2-5}$ Based on the results of the new International Association for the Study of Lung Cancer's lung cancer database for 1999 to 2010, the MST of M1a patients was 11.5 months. ${ }^{5}$ However, our results show that in both the tumor resection and open-close groups, patients with pleural seeding first detected at surgery had a better prognosis than patients with clinically diagnosed pleural seeding, with a 3-year OS of $69.2 \%$. In a multicenter study of the Japanese Clinical Oncology Group in 2000, Ichinose and colleagues ${ }^{20}$ first reported an unexpectedly good prognosis for patients with resected NSCLC with carcinomatous pleuritis of minimal disease, with 3-year and 5-year OS rates of $31.8 \%$ and $22.8 \%$, respectively. This was the largest study reported to date, with 227 patients, 100 of whom underwent main tumor resection. In 2002, another study showed the opposite results, with no survival benefit of main tumor resection in patients with NSCLC with minor malignant pleural effusion. ${ }^{21}$

High-resolution CT and PET detects most cases of pleural involvement or malignant pleural effusion during clinical staging. False-negative cases, such as our study patients, are in a relatively early stage of pleural metastasis. Along with postoperative chemotherapy and targeted therapy, primary tumor control in patients with unexpected and limited pleural seeding could be beneficial. In the most recent decade, several reports have described patients with NSCLC undergoing main tumor resection, despite intraoperatively diagnosed pleural seeding. ${ }^{13-18,22}$ These reports show favorable outcomes, similar to our results, with MSTs ranging from 15 to 52 months and 5-year OSs ranging from $16.3 \%$ to $42.7 \% .^{13-18}$ These studies are summarized in Table 5. ${ }^{13-18,21,22}$ In addition, a 2016 metaanalysis identified primary tumor resection as a beneficial
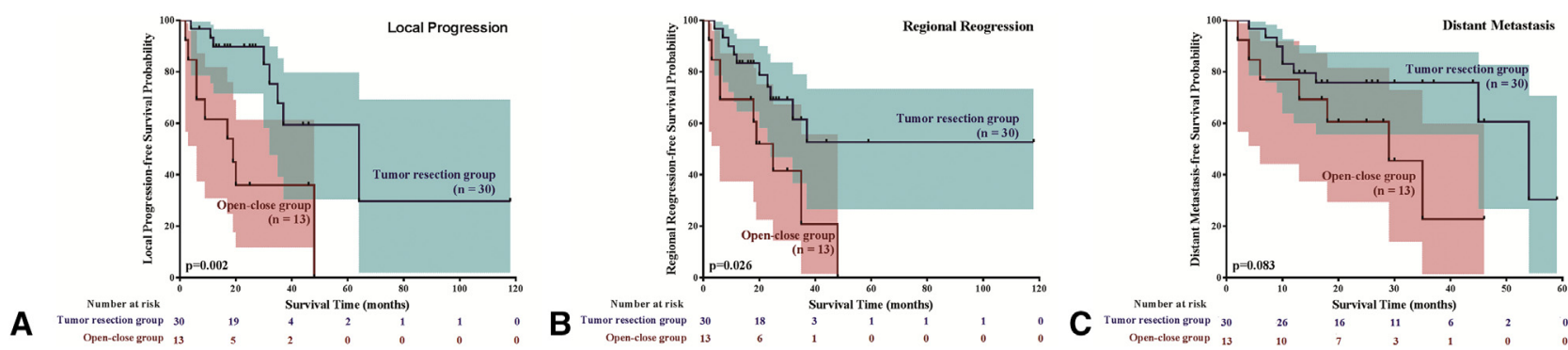

FIGURE 3. Patterns of disease progression. A, Time from surgery to detection of local progression. B, Time from surgery to detection of regional progression. C, Time from surgery to detection of distant metastasis. 
TABLE 5. Summary of reported surgical outcomes in NSCLC patients with intraoperatively diagnosed pleural seeding

\begin{tabular}{|c|c|c|c|c|c|c|c|c|c|}
\hline & $\begin{array}{l}\text { Study } \\
\text { period }\end{array}$ & $\begin{array}{c}\text { Patients } \\
\text { (tumor } \\
\text { resection/biopsy } \\
\text { alone) }\end{array}$ & $\begin{array}{c}\text { Adeno, } \\
\quad \%\end{array}$ & $\begin{array}{c}\text { EGFR } \\
\text { TKI, } \\
\%\end{array}$ & $\begin{array}{c}\text { Surgical } \\
\text { method } \\
(\text { VATS/ } \\
\text { thoracotomy), } n\end{array}$ & $\begin{array}{l}\text { Morbidity/ } \\
\text { mortality, \% }\end{array}$ & $\begin{array}{l}\text { Overall } \\
\text { survival (tumor } \\
\text { resection/biopsy } \\
\text { alone), } \%\end{array}$ & $\begin{array}{l}\text { MST (tumor } \\
\text { resection/ } \\
\text { biopsy } \\
\text { alone), mo }\end{array}$ & $\begin{array}{l}\text { Significant } \\
\text { prognostic factor } \\
\text { for better survival }\end{array}$ \\
\hline $\begin{array}{r}\text { Current } \\
\text { study }\end{array}$ & 2006-2014 & $43(30 / 13)$ & 100 & 67.4 & $42 / 1$ & $7 / 0$ & $3-y: 82.9 / 38.5$ & $64 / 35$ & Tumor resection \\
\hline $\operatorname{Ren}^{13}$ & $2005-2013$ & $83(62 / 21)$ & 65.1 & 10.8 & $19 / 64$ & $13.3 / 1.2$ & $3-y: 45.8 / 11.8$ & $35 / 17$ & $\begin{array}{l}\text { Tumor resection, } \\
\text { adenocarcinoma, } \\
\text { no pleural effusion }\end{array}$ \\
\hline $\operatorname{Ren}^{22 *}$ & 2004-2012 & $2217(128 / 2089)$ & 50 & N/A & N/A & N/A & N/A & $20 / 7$ & Tumor resection \\
\hline Yun $^{14}$ & 2000-2011 & $78(36 / 42)$ & 87.2 & 59 & $0 / 78$ & $6.4 / 0$ & $\begin{array}{l}3-y: 66.7 / 41.1 \\
5-y: 42.7 / 15.2\end{array}$ & $52 / 33$ & Tumor resection \\
\hline $\operatorname{Liu}^{15} \dagger$ & 2004-2008 & $80(80 / 0)$ & 68.8 & 0 & $0 / 80$ & N/A & $5-y: 31$ & 34.3 & $\begin{array}{l}\text { Nonsmoker, adjuvant } \\
\text { therapy }\end{array}$ \\
\hline $\mathrm{Go}^{16}$ & 1994-2012 & $25(25 / 0)$ & 64 & 8 & $0 / 25$ & N/A & $5-y: 22.2$ & 18 & $\begin{array}{l}\text { None (NO showed a } \\
\text { trend) }\end{array}$ \\
\hline Okamoto $^{17}$ & $1990-2007$ & $73(73 / 0)$ & 84.9 & 0 & $0 / 73$ & N/A & $3-y: 41.4 ; 5-y: 23.7$ & 25.9 & N0-1 \\
\hline Mordant $^{18}$ & $1983-2006$ & $32(32 / 0)$ & 65.6 & 0 & $0 / 32$ & $34 / 16$ & 5-y: 16.3 & 15 & $\begin{array}{l}\text { None (Adjuvant therapy } \\
\text { showed a trend) }\end{array}$ \\
\hline Sawabata $^{21} \ddagger$ & $1980-1994$ & $43(25 / 18)$ & 88.4 & 0 & $0 / 43$ & N/A & $5-y: 9-10 / 0$ & $13-34 / 17$ & $\begin{array}{l}\text { None (Tumor resection } \\
\text { is not beneficial for } \\
\text { survival.) }\end{array}$ \\
\hline
\end{tabular}

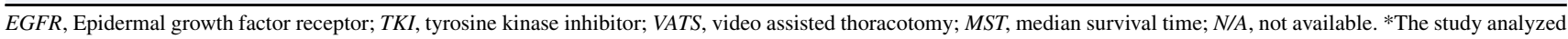
NSCLC patients with ipsilateral malignant pleural effusion from the Surveillance, Epidemiology, and End Results (SEER) registry patients. $†$ The study analyzed NSCLC patients with M1a disease who underwent surgical resection, including preoperatively diagnosed and intraoperatively diagnosed M1a disease (pleura/pericardial nodules, pleura/pericardial effusion, contra/bilateral lung nodules). $\ddagger$ The study analyzed NSCLC patients with malignant minor pleural effusion $(<300 \mathrm{~mL})$, including 16 patients of pleural dissemination that was diagnosed during surgery. The median survival time and 5-year overall survival were 13 months and $9 \%$ for complete tumor resection group ( $\mathrm{n}=11$ ); 34 months and $10 \%$ for incomplete tumor resection group $(\mathrm{n}=14)$; and 17 months and $0 \%$ for biopsy alone group $(\mathrm{n}=18)$.

prognostic factor in patients with NSCLC with intraoperatively diagnosed malignant pleural disease. ${ }^{23}$

Our findings demonstrate superior PFS and OS rates in the tumor resection group compared with the open-close group. Ren and colleagues ${ }^{13}$ reported that main tumor resection conveyed survival benefits superior to those for pleural biopsy alone (3-year OS, $45.8 \%$ vs $11.8 \%$ ). Yun and colleagues ${ }^{14}$ also found that main tumor excision increased long-term survival in patients with NSCLC with localized pleural seeding first detected intraoperatively. Although the surgical time was significantly longer in the tumor resection group than in the open-close group, main tumor resection did not increase morbidity or mortality (Video 1). ${ }^{13,14}$

Lobectomy remains the standard treatment for earlystage NSCLC. ${ }^{24,25}$ Sublobar resection is generally considered to have inferior survival to that for lobectomy, and is considered for patients with major comorbidities contraindicated for lobectomy. ${ }^{25,26}$ Recent studies have shown that survival following wedge resection might be superior to that for stereotactic body radiotherapy for early-stage NSCLC. ${ }^{27,28}$ Of the 30 patients in our study's tumor resection group, 13 underwent lobectomy and 17 underwent sublobar resection. In the 13 patients with lobectomy, tumors were located centrally and could not be resected by sublobar resection. There were no significant between-group differences in OS and PFS. Several previous studies have shown similar results, with no significant survival differences between extensive resection (pneumonectomy, bilobectomy, and lobectomy) and limited resection (wedge resection and segmentectomy). ${ }^{15,16,18}$ Okamoto and colleagues ${ }^{17}$ reported much worse outcomes in patients who underwent pneumonectomy compared with those who underwent more limited

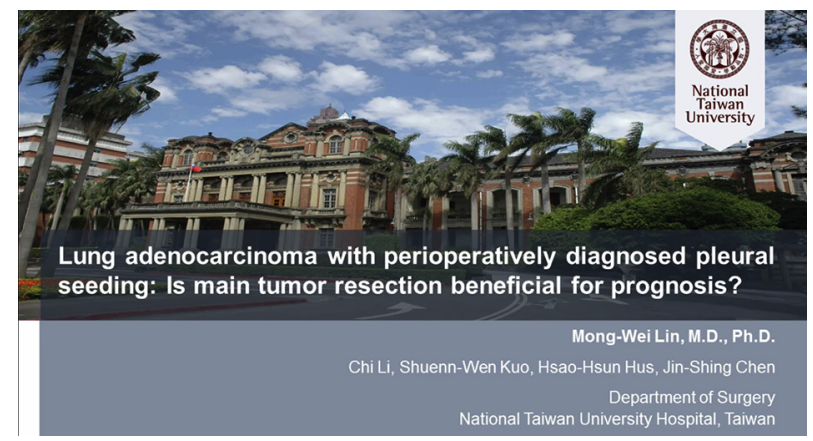

VIDEO 1. Dr Mong-Wei Lin explaining the importance of the work to the readers of the journal and the community of thoracic surgeons worldwide. Video available at: http://www.jtcvsonline.org/article/S0022-5223(17) 32730-7/fulltext. 
resection $(P=.013)$. For M1a patients, main tumor resection may serve as a debulking surgery before multimodality adjuvant therapy for tumor cell cytoreduction, rather than curative surgery. Therefore, the treatment goal would be main tumor resection rather than extensive resection of uninvolved lung parenchyma.

Several studies have reported numerous prognostic factors for PFS and OS, including adenocarcinoma histology, absence of pleural effusion, nonsmoker, administration of adjuvant therapy, and N0-1 lymph node staging. ${ }^{13-18}$ In this study, there was no significant survival difference between N0 and N1-2 lymph node staging. We hypothesized that carcinomatous pleuritis without lymph node metastasis is related to visceral pleural invasion and local tumor extension. $^{29}$ Although lymph node metastasis is a well-established prognostic factor, the degree of pleural nodule dissemination may play a more important role in the prognosis of patients with carcinomatous pleuritis. However, there remains a discrepancy in $\mathrm{N}$ status between clinical and pathological $\mathrm{N}$ stage, which may lead to bias in survival analyses. ${ }^{16}$ Although the results are not identical for these studies, the reported prognostic factors may help surgeons select patients for curative surgery and more accurately predict surgical outcomes.

Our results showed better surgical outcomes than those reported previously. Actually, more recent studies have shown a trend toward better survival than reported in earlier studies (Table 5), ${ }^{13-18}$ which may be related to improvements in multimodality lung cancer treatment and surgical techniques. Twenty-nine patients $(67.4 \%)$ in this study received EGFR TKI treatment. In addition, 4 patients $(9.3 \%)$ received ALK TKI, and 1 patient underwent a second surgery for radical pleurectomy and photodynamic therapy. Improvements in adjuvant therapies may further improve surgical outcomes for patients with unexpected M1a disease. The popularity of postoperative therapies, which are covered by the National Health Insurance of Taiwan, also accounts for the improved OS of both groups compared with that previously reported for M1a patients. ${ }^{30}$ Accessibility of the main tumor and the surgery's simplicity also affect decision making when surgeons face intraoperatively diagnosed pleural seeding. In our study, all patients underwent thoracoscopic surgery, and only 1 patient required conversion to thoracotomy for hemostasis. Advances in minimally invasive surgery for treating lung cancer, including single-port VATS, nonintubated VATS, and robotic-assisted thoracoscopic surgery with accurate intraoperative tumor localization, may minimize surgery-related morbidity and mortality, shorten hospital stays, and improve surgical outcomes. ${ }^{11,12,31-35}$

We acknowledge several limitations of this study. As a retrospective, single-institution study, time-trend bias and patient-selection bias were inevitable. We selected the study duration to incorporate most of the EGFR TKI era and to minimize the influence of the introduction of targeted therapy. Compared with previous studies, ${ }^{13-18}$ our relatively short study period should help minimize time-trend biases. Patient selection bias existed in the comparison of these 2 groups. A higher T stage and more diffused pleural nodules may be associated with a surgeon's tendency to select openclose procedures. The study cohort was exclusively Asian, with a high proportion of nonsmoking women with $E G F R$ mutations, which are independently favorable risk factors. These factors may have contributed to the excellent survival in this series, and thus extrapolation to other NSCLC populations should be done with caution. Our study results should be validated in other areas of the world. The small number of cases is another limitation. Owing to the low incidence of unexpected pleural seeding found intraoperatively, a larger multi-institutional randomized study is needed to validate our results.

\section{CONCLUSIONS}

Based on our results and current evidence, main tumor and visible pleural nodule resection followed by multimodality adjuvant therapy may achieve better OS and PFS than pleural biopsy alone in patients with lung adenocarcinoma with intraoperatively diagnosed pleural seeding. The survival benefit may be related to patients having smaller tumors and more limited pleural disease. More extensive surgeries do not suggest a survival benefit. Our results suggest that patients may undergo sublobar resection of the main tumor when feasible. Because this study was retrospective with a small number of patients, further prospective randomized trials are warranted to validate our results.

\section{Webcas}

You can watch a Webcast of this AATS meeting presentation by going to: https://aats.blob.core.windows.net/media/ 17AM/2017-05-03/RM312/05-03-17_Room312_0914_Lin. mp4.

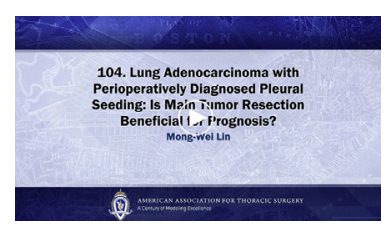

\section{Conflict of Interest Statement}

Authors have nothing to disclose with regard to commercial support.

We thank Dr Chin-Hao Chang and Hui-Hsuan Hsu, Department of Medical Research, National Taiwan University Hospital for statistical assistance, and Pei-Chen Hsu for assistance with figure production. 


\section{References}

1. American Cancer Society. Cancer Facts \& Figures 2015. Atlanta: American Cancer Society; 2015.

2. Ettinger DS, Wood DE, Akerley W, Bazhenova LA, Borghaei H, Camidge DR, et al. Non-small cell lung cancer, version 6. 2015. J Natl Compr Canc Netw. 2015;13:515-24.

3. American Joint Committee on Cancer. Lung. In: Edge S, Byrd DR, Compton CC, Fritz AG, Greene F, Trotti A, eds. AJCC Cancer Staging Manual. 7th ed. New York: Springer; 2010:253-70.

4. American Joint Committee on Cancer. Lung. In: Rami-Porta R, Asamura H, Travis WD, Rusch VW, eds. AJCC Cancer Staging Manual. 8th ed. New York: Springer; 2017:431-56.

5. Eberhardt WE, Mitchell A, Crowley J, Kondo H, Kim YT, Turrisi A III, et al. The IASLC lung cancer staging project: proposals for the revision of the M descriptors in the forthcoming eighth edition of the TNM classification of lung cancer. $J$ Thorac Oncol. 2015;10:1515-22.

6. Heffner JE, Klein JS. Recent advances in the diagnosis and management of malignant pleural effusions. Mayo Clin Proc. 2008;83:235-50.

7. Mordant P, Rivera C, Legras A, Le Pimpec Barthes F, Riquet M. Current readings: the most influential and recent studies regarding resection of lung cancer in M1a disease. Semin Thorac Cardiovasc Surg. 2013;25:251-5.

8. Rajan A, Schrump DS. Precision therapy for lung cancer: tyrosine kinase inhibitors and beyond. Semin Thorac Cardiovasc Surg. 2015;27:36-48.

9. Lin MW, Wu CT, Shih JY, Chang YL, Yang PC. Clinicopathologic characteristics and prognostic significance of EGFR and p53 mutations in surgically resected lung adenocarcinomas $\leq 2 \mathrm{~cm}$ in maximal dimension. J Surg Oncol. 2014;110:99-106.

10. Lang-Lazdunski L, Bille A, Papa S, Marshall S, Lal R, Galeone C, et al. Pleurectomy/decortication, hyperthermic pleural lavage with povidone-iodine, prophylactic radiotherapy, and systemic chemotherapy in patients with malignant pleural mesothelioma: a 10-year experience. J Thorac Cardiovasc Surg. 2015; 149:558-65; discussion 565-6.

11. Fiore JF Jr, Bejjani J, Conrad K, Niculiseanu P, Landry T, Lee L, et al. Systematic review of the influence of enhanced recovery pathways in elective lung resection. J Thorac Cardiovasc Surg. 2016;151:708-15.e6.

12. Lin MW, Tseng YH, Lee YF, Hsieh MS, Ko WC, Chen JY, et al. Computed tomography-guided patent blue vital dye localization of pulmonary nodules in uniportal thoracoscopy. J Thorac Cardiovasc Surg. 2016; 152:535-44.e2.

13. Ren YJ, She YL, Dai CY, Jiang GN, Fei K, Chen C. Primary tumour resection showed survival benefits for non-small-cell lung cancers with unexpected malignant pleural dissemination. Interact Cardiovasc Thorac Surg. 2016;22:321-6.

14. Yun JK, Kim MA, Choi CM, Choi SH, Kim YH, Kim DK, et al. Surgical outcomes after pulmonary resection for non-small cell lung cancer with localized pleural seeding first detected during surgery. Thorac Cardiovasc Surg. 2015 [Epub ahead of print].

15. Liu T, Liu H, Wang G, Zhang C, Liu B. Survival of M1 a non-small cell lung cancer treated surgically: a retrospective single-center study. Thorac Cardiovasc Surg. 2015;63:577-82.

16. Go T, Misaki N, Matsuura N, Chang SS, Tarumi S, Yokomise H. Role of surgery in multi-modality treatment for carcinomatous pleuritis in patients with nonsmall cell lung cancer. Surg Today. 2015;45:197-202.

17. Okamoto T, Iwata T, Mizobuchi T, Hoshino H, Moriya Y, Yoshida S, et al. Pulmonary resection for lung cancer with malignant pleural disease first detected at thoracotomy. Eur J Cardiothorac Surg. 2012;41:25-30.

18. Mordant P, Arame A, Foucault C, Dujon A, Le Pimpec Barthes F, Riquet M. Surgery for metastatic pleural extension of non-small-cell lung cancer. Eur J Cardiothorac Surg. 2011;40:1444-9.

19. Iida T, Shiba M, Yoshino I, Miyaoka E, Asamura H, Date H, et al. Surgical intervention for non-small-cell lung cancer patients with pleural carcinomatosis: results from the Japanese lung cancer registry in 2004. J Thorac Oncol. 2015;10: 1076-82.

20. Ichinose Y, Tsuchiya R, Koike T, Kuwahara O, Nakagawa K, Yamato Y, et al. Prognosis of resected non-small cell lung cancer patients with carcinomatous pleuritis of minimal disease. Lung Cancer. 2001;32:55-60.

21. Sawabata N, Matsumura A, Motohiro A, Osaka Y, Gennga K, Fukai S, et al. Malignant minor pleural effusion detected on thoracotomy for patients with nonsmall cell lung cancer: is tumor resection beneficial for prognosis? Ann Thorac Surg. 2002;73:412-5.

22. Ren Y, Dai C, Shen J, Liu Y, Xie D, Zheng H, et al. The prognosis after contraindicated surgery of NSCLC patients with malignant pleural effusion (M1a) may be better than expected. Oncotarget. 2016;7:26856-65.
23. Xu Y, Chen N, Wang Z, Zhang Y, Mei J, Liu C, et al. Should primary tumor be resected for non-small cell lung cancer with malignant pleural disease unexpectedly found during operation?-a systemic review and meta-analysis. J Thorac Dis. 2016;8:2843-52.

24. Howington JA, Blum MG, Chang AC, Balekian AA, Murthy SC. Treatment of stage I and II non-small cell lung cancer: diagnosis and management of lung cancer, 3rd ed: American College of Chest Physicians evidence-based clinical practice guidelines. Chest. 2013;143(5 Suppl):e278S-313S.

25. Ginsberg RJ, Rubinstein LV. Randomized trial of lobectomy versus limited resection for T1 N0 non-small cell lung cancer. Lung Cancer Study Group. Ann Thorac Surg. 1995;60:615-22; discussion 622-3.

26. Rami-Porta R, Tsuboi M. Sublobar resection for lung cancer. Eur Respir J. 2009; 33:426-35.

27. Matsuo Y, Chen F, Hamaji M, Kawaguchi A, Ueki N, Nagata Y, et al. Comparison of long-term survival outcomes between stereotactic body radiotherapy and sublobar resection for stage I non-small-cell lung cancer in patients at high risk for lobectomy: a propensity score matching analysis. Eur J Cancer. 2014;50:2932-8.

28. Li M, Yang X, Chen Y, Yang X, Dai X, Sun F, et al. Stereotactic body radiotherapy or stereotactic ablative radiotherapy versus surgery for patients with T1-3N0M0 non-small cell lung cancer: a systematic review and meta-analysis. Onco Targets Ther. 2017;10:2885-92.

29. Manac'h D, Riquet M, Medioni J, Le Pimpec-Barthes F, Dujon A, Danel C. Visceral pleura invasion by non-small cell lung cancer: an underrated bad prognostic factor. Ann Thorac Surg. 2001;71:1088-93.

30. Huang HL, Kung PT, Chiu CF, Wang YH, Tsai WC. Factors associated with lung cancer patients refusing treatment and their survival: a national cohort study under a universal health insurance in Taiwan. PLoS One. 2014;9:e101731.

31. Yamamoto K, Ohsumi A, Kojima F, Imanishi N, Matsuoka K, Ueda M, et al. Long-term survival after video-assisted thoracic surgery lobectomy for primary lung cancer. Ann Thorac Surg. 2010;89:353-9.

32. Dylewski MR, Lazzaro R, Abbas AE. Complete port-access robotic-assisted lobectomy utilizing three-arm technique without a transthoracic utility incision. In: Kim KC, ed. Robotics in General Surgery. 1st ed. New York: Springer; 2014:69-84.

33. Villamizar NR, Darrabie M, Hanna J, Onaitis MW, Tong BC, D’Amico TA, et al. Impact of $\mathrm{T}$ status and $\mathrm{N}$ status on perioperative outcomes after thoracoscopic lobectomy for lung cancer. J Thorac Cardiovasc Surg. 2013;145:514-21.

34. Abbas A, Kadakia S, Ambur V, Muro K, Kaiser L. Intraoperative electromagnetic navigational bronchoscopic localization of small, deep, or subsolid pulmonary nodules. J Thorac Cardiovasc Surg. 2017;153:1581-90.

35. Cerfolio RJ, Cichos KH, Wei B, Minnich DJ. Robotic lobectomy can be taught while maintaining quality patient outcomes. J Thorac Cardiovasc Surg. 2016; 152:991-7.

Key Words: adenocarcinoma, lung cancer, pleural metastasis, prognosis, surgery

\section{Discussion}

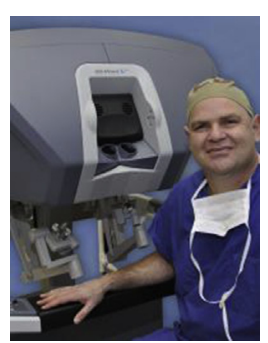

Dr Benny Weksler (Memphis, Tenn). Dr Lin, congratulations on an excellent presentation and thank you for sending me the manuscript way ahead of time. You present survival data for 43 lung cancer patients with adenocarcinoma, 30 who underwent resection of primary tumors and pleural metastases and 13 who did not have any resection, and you conclude that survival is improved with resection of pleural implant. It is certainly a provocative study that challenges our current management of these patients.

Besides the small numbers, I have significant concerns regarding selection bias in your study. It would be logical 
to assume that patients who were not resected had less pleural nodules and less tumor burden.

I have 3 questions that I will take one at a time, please. Number one is, how many tumor nodules were present in each of the 2 groups?

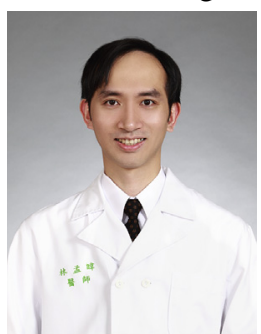

Dr Mong-Wei Lin (Taipei, Taiwan). There was only one single lung tumor in all patients. We excluded 7 patients with multiple lung tumors from our study. All patients in the study population had single lung nodule.

Dr Weksler. I was under the impression that you showed 2 nodules in the beginning, so I apologize.

Let's say that your data is confirmed. How many nodules do you think will be too many for resection? I mean, if you resect 1 , why not 2 , if you resect 2 , why not 3 ?

Dr Lin. That's an important question.

Dr Weksler. Hold on. It was called to my attention that I was talking about the number of pleural nodules, not lung nodules. So my first question regards pleural nodules. How many pleural nodules were in one group and in the other? Thank you.

Dr Lin. Thanks for your excellent comment. This is an important question. Actually, I have to acknowledge that it is difficult to clearly clarify the degree of pleural nodules in 2 groups in a retrospective study, since we only checked the operative notes and pictures. However, we have 7 thoracic surgeons in our hospital, and some surgeons strictly obey the current guideline for stage IV disease and always do open-close surgery for such cases, and some surgeons may consider doing main tumor resection and radical pleural nodule resection for such cases.

So further, I want to state that single surgeon may do only either open-close surgery or main tumor resection, but not always single surgeon to select the method. For example, for me, I used to always do open-close surgery since I prefer to operate under the current guideline. So that may reduce the selection bias. But to tell the truth, you are right, because I cannot answer the question of exactly how many pleural nodules in each of the 2 groups.

Dr Weksler. But now that your group has studied this, how many nodules would be too many to resect from the pleura? Would you resect 2, 3, 4? And an extension of this question, if you have both visceral and pleural and parietal pleural metastases, would you do a pleurectomy and decortication for those patients?

Dr Lin. Thanks for your important question. I reviewed the study, and there were 2 patients in the tumor resection group who had visceral pleural nodules, and these nodules were resected by wedge resection. It is important that we prefer to limit the resection for patients with limited pleural nodules.

I think this issue is somehow like the debate on $\mathrm{N} 2$ disease we just heard 1 or 2 days ago, that a single-station small N2 disease may be possible for surgical treatment but for bulky multiple-station N2 disease, surgery is not preferred. So I think it is somehow similar in such condition that lung tumor with localized pleural nodules may be indicated for main tumor resection; since we open the wound, we resect it.

Another important issue is that we have to add adjuvant therapy for such patients. In our series, not only EGFR TKI, but there were 4 patients without EGFR mutation we gave crizotinib, and even 1 patient in the open-close group we performed a second operation of photodynamic therapy. So, what I want to say is that with the improvement of multimodality adjuvant therapy, I think it would be more and more reasonable to perform surgery for those who used to be regarded as inoperable patients.

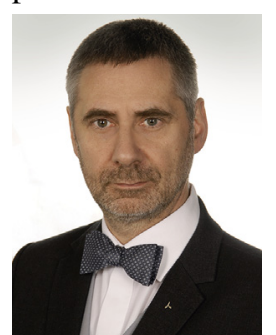

Dr Jaroslaw Kuzdzal (Krakow, Poland). I would like to congratulate you for the study. I think that it is important based not on the attempt to clarify this complex problem totally, because it is not possible at this stage, but it shows that certainly there is a subgroup of patients with pleural M1 deposits who can benefit from extensive surgery. We are unable nowadays to clearly tell apart those patients who could benefit or who cannot. But what is absolutely great in this study, which I would like to congratulate again, is that it is breaking boundaries, which is a very important thing for progress in our specialty. We have seen the same situation in early metastatic lung cancer, which is now being treated surgically or using other methods with a curative intent.

So congratulations again for the study. I think it is the beginning of a changing of mind and other studies that will clarify this issue more in the future.

Dr Lin. Thank you for your kind comment. 

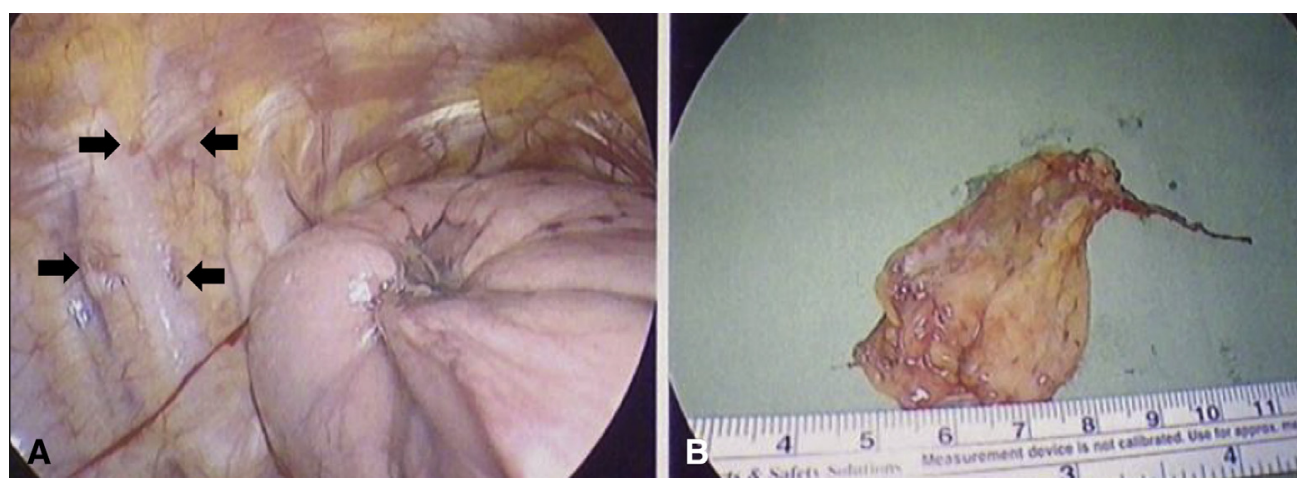

FIGURE E1. Pleurectomy was performed after the surgeon regarded the pleural metastasis as completely resectable. A, Thoracoscopic view of the right upper lobe main tumor and pleural metastasis (arrows). Although there were more than 3 pleural nodules and the patient was thus considered to have diffused pleural metastasis, these grossly visible nodules were located in the same area and could be completely resectable. B, Parietal pleura after video-assisted thoracoscopic surgery pleurectomy.
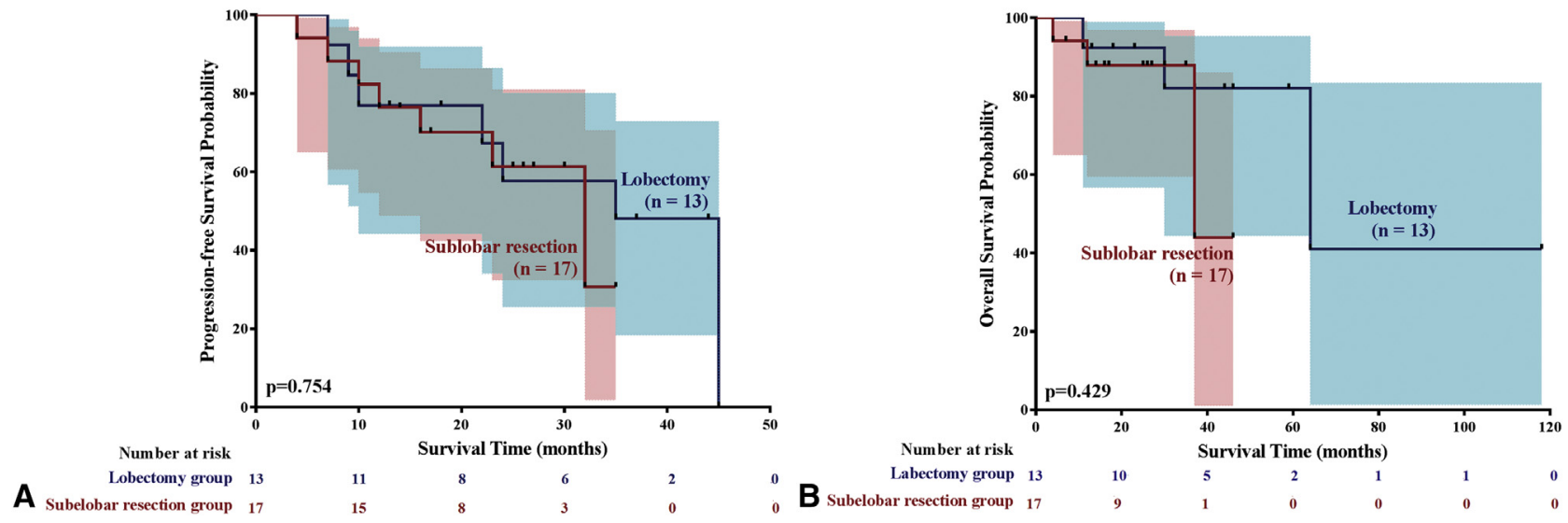

FIGURE E2. Kaplan-Meier survival curves of progression-free survival (A) and overall survival (B) of patients based on surgical method. 